\title{
Desertification dynamic and the relative roles of climate change and human activities in desertification in the Heihe River Basin based on NPP
}

\author{
Wei ZHOU, ZhengGuo SUN, JianLong LI*, ChengCheng GANG, ChaoBin ZHANG \\ School of Life Science, Nanjing University, Nanjing 210093, China
}

\begin{abstract}
Relative roles of climate change and human activities in desertification are the hotspot of research on desertification dynamic and its driving mechanism. To overcome the shortcomings of existing studies, this paper selected net primary productivity (NPP) as an indicator to analyze desertification dynamic and its impact factors. In addition, the change trends of actual NPP, potential NPP and HNPP (human appropriation of NPP, the difference between potential NPP and actual NPP) were used to analyze the desertification dynamic and calculate the relative roles of climate change, human activities and a combination of the two factors in desertification. In this study, the Moderate Resolution Imaging Spectroradiometer (MODIS)-Normalised Difference Vegetation Index (NDVI) and meteorological data were utilized to drive the Carnegie-Ames-Stanford Approach (CASA) model to calculate the actual NPP from 2001 to 2010 in the Heihe River Basin. Potential NPP was estimated using the Thornthwaite Memorial model. Results showed that $61 \%$ of the whole basin area underwent land degradation, of which $90.5 \%$ was caused by human activities, $8.6 \%$ by climate change, and $0.9 \%$ by a combination of the two factors. On the contrary, $1.5 \%$ of desertification reversion area was caused by human activities and $90.7 \%$ by climate change, the rest $7.8 \%$ by a combination of the two factors. Moreover, it was demonstrated that $95.9 \%$ of the total actual NPP decrease was induced by human activities, while $69.3 \%$ of the total actual NPP increase was caused by climate change. The results revealed that climate change dominated desertification reversion, while human activities dominated desertification expansion. Moreover, the relative roles of both climate change and human activities in desertification possessed great spatial heterogeneity. Additionally, ecological protection policies should be enhanced in the Heihe River Basin to prevent desertification expansion under the condition of climate change.
\end{abstract}

Keywords: desertification; net primary productivity (NPP); climate change; human activities; quantitative assessment; Heihe River Basin

Citation: Wei ZHOU, ZhengGuo SUN, JianLong LI, ChengCheng GANG, ChaoBin ZHANG. 2013. Desertification dynamic and the relative roles of climate change and human activities in desertification in the Heihe River Basin based on NPP. Journal of Arid Land, 5(4): 465-479. doi: $10.1007 / \mathrm{s} 40333-013-0181-\mathrm{z}$

Desertification or land degradation is regarded as one of the most serious social-economic-environmental issues in arid, semi-arid and dry sub-humid areas. Desertification is the result of complex interactions among various factors, including climate change and human activities (UNCCD, 1994). Additionally, the quantitative assessment of the driving forces of desertification has become the focus of desertification re- search (Xu et al., 2010). Although many researches assessed the relative roles of climate and human factors in desertification, there remains a great deal of disagreement about the dominant driving factors of desertification (Rasmussen et al., 2001; Wang et al., 2006; Zheng et al., 2006). For example, some researchers attributed Sudan's Sahel desertification to rainfall change rather than human activities (Nichol-

*Corresponding author: JianLong Li (E-mail: jlli2008@nju.edu.cn) Received 2012-10-29; revised 2012-11-30; accepted 2013-02-16

(C) Xinjiang Institute of Ecology and Geography, Chinese Academy of Sciences, Science Press and Springer-Verlag Berlin Heidelberg 2013 
son et al., 1998; Prince et al., 1998; Nicholson, 2005). However, many researchers have attributed the rapid desertification in Northern China to a long-term overgrazing, overcutting, and excessive conversion of grassland to cropland (Wang and $\mathrm{Zhu}, 2003$; Wang et al., 2006), while others found that poor climate conditions such as drought, severe wind erosion, and fluctuation of temperature were the primary causes for desertification spread (Hai et al., 2002; Sun and Li, 2002). Nevertheless, some recent studies showed that human activities controlled the desertification reversion in some regions of Northern China ( $\mathrm{Xu}$ et al., 2010; Wang et al., 2012).

In fact, an optimal quantitative assessment method is crucial for assessing the relative roles of climate change and human activities in desertification (Verón et al., 2006). The quantitative methods in previous studies mainly utilized statistical analyses, including regression model (Zhang et al., 2003), correlation analysis (Chang et al., 2003), and principal component analysis (Lieth and Box, 1972). Recently, some studies have selected vegetation dynamic as an indicator to distinguish human activities from climate change in their impact on desertification (Wessels et al., 2007, 2008; Xu et al., 2010; Zhang et al., 2011). Vegetation dynamic was measured by net primary productivity (NPP) and has been utilized as an indicator to distinguish climate and human impacts on ecosystems (Zheng et al., 2006; Wessels et al., 2008; Xu et al., 2010). Especially in recent years, some researchers used HNPP (human appropriation of NPP) as an indicator to evaluate the impact of human activities on regional and global ecosystems (Zhang et al., 2011).

Desertification has led to serious environmental and social problems, such as biological productivity decline, soil quality degradation, biodiversity loss, and the increase of sand storm events (Le Houérou, 1996). In addition, it also leads to the decrease of carbon sequestration and the net releases of carbon dioxide into the atmosphere (Alcamo and Bennett, 2003), which ultimately influences the carbon cycle of ecosystems and restricts the sustainable development of social economy. In order to mitigate the hazards of desertification and environment degradation, Chinese government has implemented some ecological conserva- tion projects such as the Grain for Green Program, the Natural Forest Protection Project, and the project of returning grazing land to grassland in the late 1990s and early 2000s, which led to the relative decrease of desertification areas in China (Wang et al., 2004a; State Forestry Administration, 2007).

The Heihe River Basin is located in the arid region of Northwest China and experiences serious environmental deterioration because of its population growth, economic development and climate change ( $\mathrm{Lu}$ et al., 2008). It is surrounded by Badain Jaran Desert and is one of the main origins of sandstorms in China (Wang et al., 2004b). However, few researches were conducted to explore the desertification dynamic and quantitatively assess its driving factors in this basin. Therefore, in the present study, we designed a method to quantitatively assess the relative roles of climate change and human activities in desertification. In order to facilitate the quantitative analysis, we selected three kinds of NPP. One is the potential NPP, an ideal vegetation productivity that is only determined by climate change in the absence of human activities and can be estimated by the Thornthwaite Memorial model (Lieth and Box, 1972). Another is actual NPP, a real vegetation productivity that is influenced by both climate and human factors and can be calculated using the Carnegie-Ames-Stanford Approach (CASA) model (Potter et al., 1993). The third is HNPP, a vegetation productivity that equals the difference between potential NPP and actual NPP, and can be used to estimate the impact of human activities on desertification. In this study, the change trends of actual NPP, potential NPP and HNPP were used to analyze the desertification dynamic and the relative roles of climate change and human activities and a combination of the two factors in desertification. By this analysis, we can better understand the driving mechanism of desertification and determine the dominant driving factors of desertification, and then provide some suggestions for the ecological restoration of land degradation in the Heihe River Basin.

\section{Materials and Methods}

\subsection{Study area}

The Heihe River Basin is the second largest inland 
river basin in the arid region of Northwest China. It is located between $37^{\circ} 44^{\prime}-42^{\circ} 42^{\prime} \mathrm{N}$ and $96^{\circ} 42^{\prime}-102^{\circ} 08^{\prime} \mathrm{E}$ and covers an area of approximately $128,900 \mathrm{~km}^{2}$. Administratively, the basin includes part of Qilian county of Qinghai province, some counties and cities of Gansu province, and part of Ejin Banner in Alxa League of Inner Mongolia autonomous region (Fig. 1).
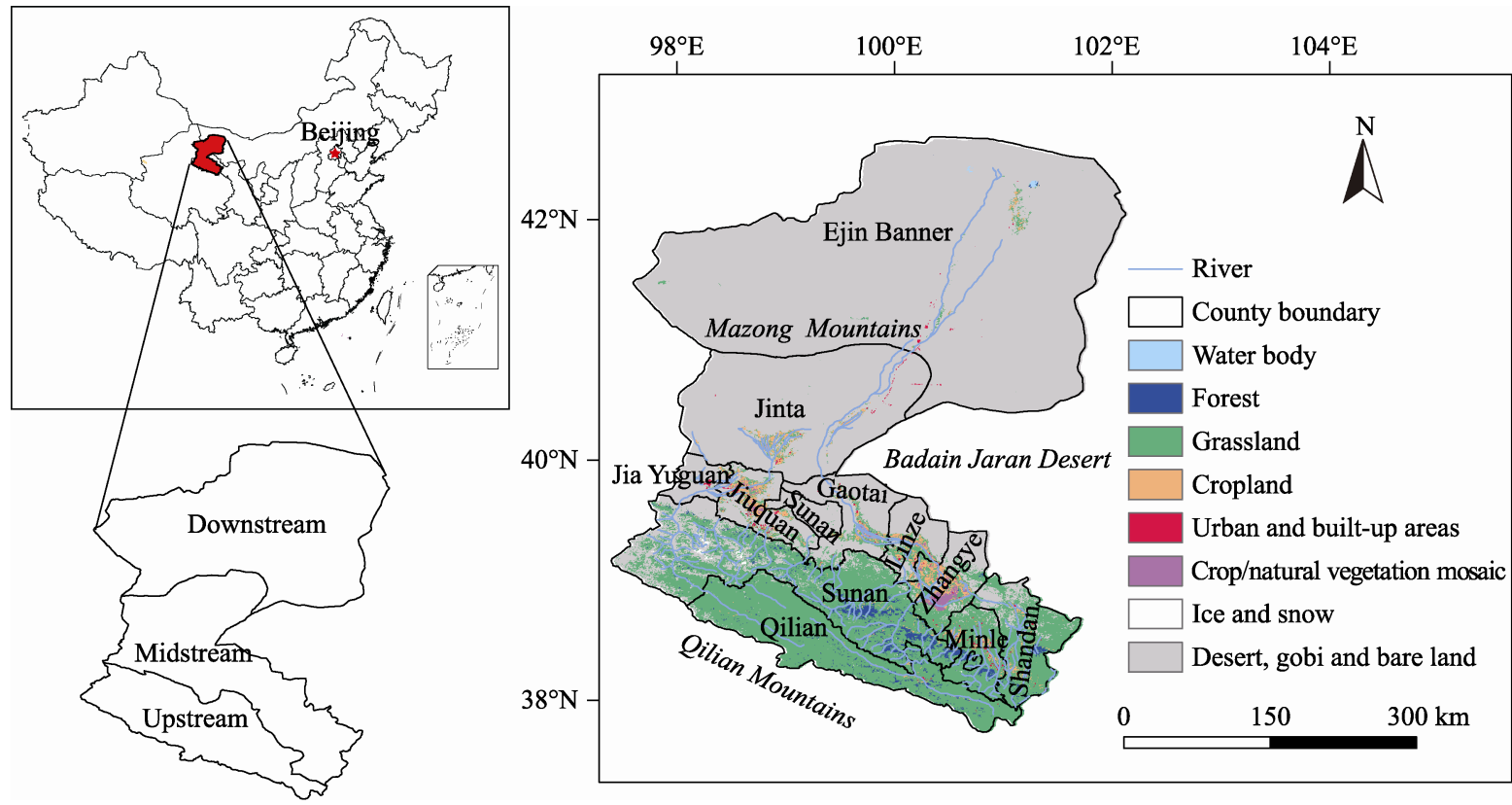

Fig. 1 The location of the study area and its land use

Geographic differentiation in the basin is evident. From south to north of the basin, there are three major geomorphologic units: the southern Qilian Mountains in the upstream, the Hexi Corridor in the midstream, and the northern Alxa Plateau in the downstream (Li et al., 2001).

The southern Qilian Mountains, with remarkable vertical zonality, is the area of runoff generation and water resources formation. The elevation of the area ranges from 2,000 to $5,500 \mathrm{~m}$ and the mean annual precipitation increases from about $250 \mathrm{~mm}$ in the low mountain zone to $500 \mathrm{~mm}$ in the high mountain zone. In addition, the land covers are mainly natural ecosystems, including cold deserts, mountain forests and shrubs, alpine meadows and steppe, ice and snow (Ma and Frank, 2006).

The middle Hexi Corridor, with an area of 17,000 $\mathrm{km}^{2}$, is sandwiched between the southern Qilian Mountains and the northern Mazong Mountains. The elevation of the area decreases from 2,000 to 1,000 m, correspondent with a decrease of the mean annual precipitation from $250 \mathrm{~mm}$ to less than $100 \mathrm{~mm}$ (Li et al., 2001). Here various artificial oases exist, including the counties of Mingle, Shandan, Linze, Gaotai and Jinta, and the cities of Zhangye, Jiuquan and Jia Yuguan. Irrigated agriculture dominated by farmland vegetation develops very well, but with a high consumption of water resources. Meanwhile, gobi and desert are largely scattered in the midstream.

The northern Alxa Plateau, with a mean elevation of about 1,000 $\mathrm{m}$ and mean annual precipitation of 50 $\mathrm{mm}$, is mainly occupied by gobi, desert and bare land. The natural oases dominated by meadows and salinized meadows are relatively small and fragmented and easily disturbed; moreover, the extensive exploitation of the water and land resources in the upstream and midstream of the basin and climate warming have led to a sharp decrease of water resources in the downstream. This resulted in the severe deterioration of the eco-environment in the Ejin Banner (Lu et al., 2008): forests diminished quickly and the lakes in the downstream disappeared, turning into marsh-salinized and meadow-salt deserts (Li et al., 2001).

Additionally, the Heihe River Basin has experi- 
enced rapid socioeconomic development and population growth. Nevertheless, the pressure from population growth and socioeconomic development has led to land degradation. Meanwhile, it has become one of the typical desertification regions in Northwest China, with diminishing natural forests, grassland areas and productivities, and the expansion of desertification and salinization (Lu et al., 2008). Therefore, the quantitative assessment of desertification is essential to desertification control and it in turn benefits sandstorm decrease.

\subsection{Data source and processing}

Normalised Difference Vegetation Index (NDVI), meteorological data, and geographical data were used to estimate NPP. We downloaded 16-day, 500-m Moderate Resolution Imaging Spectroradiometer (MODIS)-NDVI (MOD13A1) data from 2001 to 2010. These NDVI data were obtained from the Terra MODIS of the National Aeronautics and Space Administration of the USA, which is readily available at http://ladsweb. nascom.nasa.gov/data/search.html. The maximum-value compositing procedure was used to merge the16-day NDVI data and produce the monthly NDVI datasets. These remote sensing data were re-projected from the original Integerized Sinusoidal Projection to the Albers equal area projection and WGS-84 datum using the ArcGIS v9.3 software (ESRI, California, USA).

Monthly average temperature and total precipitation data came from 18 weather stations and total solar radiation data from 8 weather stations in and around the Heihe River Basin from 2001 to 2010; these data originated from China Meteorological Data Sharing Service Network. The inverse distance weighted (IDW) method was used to interpolate meteorological data into grid data with $500-\mathrm{mm}$ spatial resolution. The monthly NDVI and meteorological data were used to drive the CASA model to calculate actual NPP. The meteorological data required for the Thornthwaite Memorial model are annual average temperature and annual precipitation. These annual data were calculated by incorporating the 12-month meteorological data. In addition, the error analysis of predicted meteorological data with measured data was conducted (Table 1). Results indicated that there was no significant difference between measured and prediction data and the accuracy is satisfactory at $95 \%$ confidence level.

\subsection{Estimation of actual NPP}

The vegetation dynamic is very important in the process of desertification and can reflect the complex interactions between climate change and human activities (Hanafi and Jauffret, 2008). In this study, we selected the annual total actual NPP $\left(\mathrm{g} \mathrm{C}\left(\mathrm{m}^{2} \cdot \mathrm{a}\right)\right)$ as an indicator to represent the vegetation condition and assess the relative roles of climate change and human activities in desertification.

The actual NPP was calculated using the CASA model, which is a light use efficiency $(\varepsilon)$ model based

Table 1 Error analysis for the interpolated meteorological data (using year 2001 as an example)

\begin{tabular}{|c|c|c|c|c|c|c|c|c|c|}
\hline \multirow{2}{*}{ Month } & \multicolumn{3}{|c|}{ Temperature $(n=18)$} & \multicolumn{3}{|c|}{ Precipitation $(n=18)$} & \multicolumn{3}{|c|}{ Solar radiation $(n=8)$} \\
\hline & Mean error & RMSE & $R^{2}$ & Mean error & RMSE & $R^{2}$ & Mean error & RMSE & $R^{2}$ \\
\hline Jan & 0.006 & 0.958 & 0.958 & 0.289 & 0.987 & 0.789 & -1.977 & 1.087 & 0.795 \\
\hline Feb & -0.073 & 0.985 & 0.935 & 0.351 & 1.425 & 0.785 & 1.788 & 0.973 & 0.803 \\
\hline Mar & -0.135 & 0.937 & 0.859 & 0.509 & 0.958 & 0.931 & 1.727 & 0.857 & 0.796 \\
\hline Apr & -0.175 & 0.883 & 0.821 & 3.149 & 1.491 & 0.798 & 1.039 & 0.908 & 0.837 \\
\hline May & -0.124 & 0.925 & 0.842 & 0.438 & 1.677 & 0.789 & 5.963 & 1.593 & 0.778 \\
\hline Jun & -0.118 & 0.960 & 0.869 & 1.758 & 0.975 & 0.877 & 4.839 & 1.045 & 0.789 \\
\hline Jul & -0.113 & 0.883 & 0.874 & -10.026 & 1.709 & 0.781 & -1.719 & 0.897 & 0.801 \\
\hline Aug & -0.095 & 0.908 & 0.886 & -8.659 & 1.506 & 0.792 & -0.989 & 1.023 & 0.885 \\
\hline Sep & -0.098 & 0.976 & 0.893 & -4.742 & 0.997 & 0.828 & 1.848 & 0.981 & 0.879 \\
\hline Oct & -0.085 & 0.950 & 0.897 & 2.768 & 1.302 & 0.769 & 3.720 & 1.018 & 0.729 \\
\hline Nov & 0.028 & 0.875 & 0.927 & 0.481 & 1.146 & 0.748 & 1.018 & 0.989 & 0.763 \\
\hline Dec & 0.008 & 0.887 & 0.953 & -0.447 & 1.030 & 0.803 & 2.891 & 1.036 & 0.795 \\
\hline
\end{tabular}


on the resource-balance theory (Potter et al., 1993; Field et al., 1995). In the CASA model, NPP is the product of absorbed photosynthetically active radiation (APAR) and $\varepsilon$ (Potter et al., 1993). The basic principle of the model can be described as the following formula:

$$
N P P(x, t)=\operatorname{APAR}(x, t) \times \varepsilon(x, t) .
$$

Where $x$ is location (the pixel number), and $t$ is time; $\operatorname{APAR}(x, t)$ represents the canopy-absorbed incident solar radiation integrated over a given time period $\left(\mathrm{MJ} / \mathrm{m}^{2}\right)$; and $\varepsilon(x, t)$ represents the actual $\varepsilon(\mathrm{g} \mathrm{C} / \mathrm{MJ})$ of pixel $x$ in $t$ time.

Estimation of $\operatorname{APAR}(x, t)$ :

$$
\operatorname{APAR}(x, t)=\operatorname{SOL}(x, t) \times F P A R(x, t) \times 0.5 .
$$

Where $\operatorname{SOL}(x, t)$ is total solar radiation $\left(\mathrm{MJ} / \mathrm{m}^{2}\right)$ of pixel $x$ in $t$ time; $\operatorname{FPAR}(x, t)$ is the fraction of PAR (photosynthetically active radiation) absorbed by vegetation canopy, and it can be determined by NDVI (Ruimy et al., 1994; Field et al., 1998); 0.5 represents the proportion of SOL that is available for vegetation (wave length range of $0.38-0.71 \mu \mathrm{m}$ ).

Estimation of $\varepsilon(x, t)$ :

$$
\varepsilon(x, t)=T_{\varepsilon 1}(x, t) \times T_{\varepsilon 2}(x, t) \times W_{\varepsilon}(x, t) \times \varepsilon_{\max } .
$$

Where, $T_{\varepsilon 1}(x, t)$ and $T_{\varepsilon 2}(x, t)$ are temperature stress coefficients, $T_{\varepsilon 1}(x, t)$ represents the influence of extreme temperature on $\varepsilon$ (Field et al., 1995), and $T_{\varepsilon 2}(x, t)$ reflects the decrease of $\varepsilon$ when the temperature deviates from the optimal temperature (Potter et al., 1993; Field et al., 1995); $W_{\varepsilon}(x, t)$ is the water stress coefficient that indicates the reduction of $\varepsilon$ caused by moisture factor; and $\varepsilon_{\max }$ is the maximum $\varepsilon$ under ideal conditions set as different constant parameters for various vegetation types (Zhu et al., 2006). A more detailed description of this model can be found in previous research (Yu et al., 2011).

\subsection{Validation of the CASA model}

To verify the estimation accuracy of the CASA model, we used the independently observed NPP data in 50 quadrats in July 2009 in the Heihe River Basin, compared with the estimated values. Figure 2 presents the results of the correlation analysis between the observed NPP data and estimated NPP data. Due to the differences in the scale of the observed and estimated data, the estimated data were slightly larger than the field observed data. However, this would not have an impact on the results during time serial trend analysis. Meanwhile, the correlation was significant $\left(R^{2}=0.664\right.$, $P<0.001$ ), which indicates that the model's estimation accuracy is satisfactory.

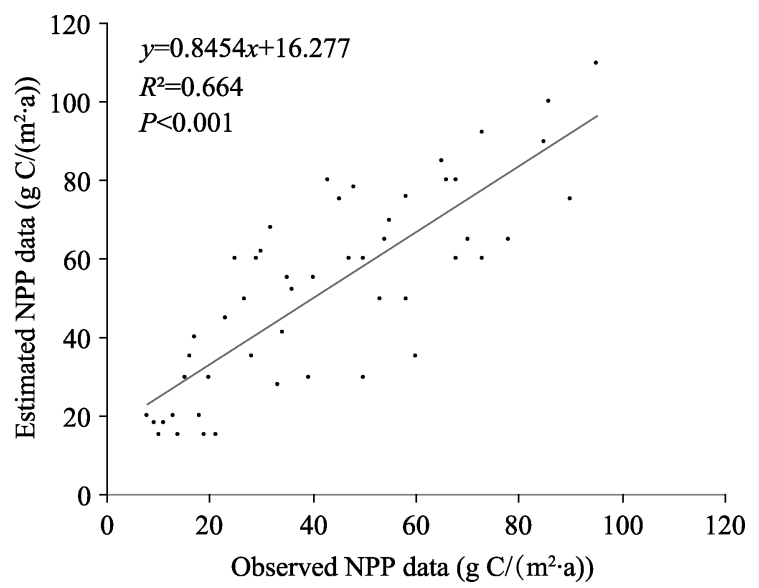

Fig. 2 The validation of the Carnegie-Ames-Stanford Approach (CASA) model in the Heihe River Basin

\subsection{Estimation of potential NPP}

Potential NPP predicts an ideal condition in the absence of human activities and is only determined by climate condition. Several climate productivity models have been developed to estimate potential NPP and these models applied different meteorological data. The Miami model (Lieth, 1975) was the first widely used model in estimating the potential NPP based on the annual mean temperature and annual precipitation. While, the Thornthwaite Memorial model was modified by introducing potential evaporation besides temperature and precipitation (Lieth and Box, 1972; Lieth, 1975). Therefore, in the present study, Thornthwaite Memorial model was used to estimate potential NPP. The model was expressed as follows:

$$
N P P=3000\left[1-e^{-0.0009695(v-20)}\right] \text {. }
$$

Where NPP is the annual total potential NPP ( $\mathrm{g}$ $\left.\mathrm{C} /\left(\mathrm{m}^{2} \cdot \mathrm{a}\right)\right)$, and $v$ is the average annual actual evapotranspiration $(\mathrm{mm})$. The calculated equations are as follows:

$$
\begin{gathered}
V=\frac{1.05 r}{\sqrt{1+(1+1.05 r / L)^{2}}}, \\
L=3000+25 t+0.05 t^{3} .
\end{gathered}
$$


Where $r$ is the annual precipitation ( $\mathrm{mm}) ; L$ is the average annual evapotranspiration ( $\mathrm{mm})$; and $t$ is the annual average temperature $\left({ }^{\circ} \mathrm{C}\right)$.

\subsection{Desertification dynamic analysis and scenario design}

The vegetation dynamic is a most intuitive manifestation of desertification progress and reflects the ecological process involved in desertification and its driving factors. The quantitative assessment method used in the present study is based on the concept that desertification dynamic is mainly caused by the change of productivity. Productivity is one of the most important land degradation dynamic indices and is easily estimated by remote sensing data. Additionally, NPP is a fundamental ecological variable which can reflect the productivity of a vegetation community and is sensitive to climate and human factors. Therefore, if the quantitative relation between the change of NPP induced by climate change and human activities are identified, it is possible to quantitatively assess the relative roles of climate and human factors in desertification progress.

In this study, we used the ordinary least-squares method to estimate the change trend of potential NPP, actual NPP and HNPP (i.e. difference between the potential NPP and actual NPP). The equation is as follows:

$$
\text { Slope }=\frac{10 \times \sum_{i=1}^{10} i \times N P P_{i}-\left(\sum_{i=1}^{10} i\right)\left(\sum_{i=1}^{10} N P P_{i}\right)}{10 \times \sum_{i=1}^{10} i^{2}-\left(\sum_{i=1}^{10} i\right)^{2}} .
$$

Where $i$ is 1 for year 2001, 2 for year 2002 and so on, until 10 for 2010; $N P P_{i}$ is the value of annual NPP in $i$ year. Slope of NPP is the average annual increase (or decrease) of the NPP from 2001 to 2010.

The total increment (or decrement) of NPP during the study period can be estimated for each pixel, using the following equation:

$$
\text { Variation }=(n-1) \times \text { slope. }
$$

Where, $n$ is 10 , i.e. the number of years from 2001 to 2010. And NPP variation calculation based on Eq. 8 is more rational compared with direct calculation of the residual of NPP in 2010 and 2001 (e.g. $\triangle \mathrm{NPP}=$ $\left.\mathrm{NPP}_{2010}-\mathrm{NPP}_{2001}\right)$.
The effect of climate change on NPP can be represented using the slope of potential NPP $\left(\mathrm{S}_{\mathrm{P}}\right)$. A positive trend of potential NPP indicates that climate change during this period benefits the growth of vegetation and the reversion of desertification. While, the negative of $\mathrm{S}_{\mathrm{P}}$ indicates that climate change is harmful to vegetation growth and desertification reversion.

The effect of human activities on NPP is based on the slope of HNPP $\left(\mathrm{S}_{\mathrm{H}}\right)$. If $\mathrm{S}_{\mathrm{H}}$ are negative, human activities during this period benefit the growth of vegetation and human-dominated desertification reversion occurs. Inversely, positive $\mathrm{S}_{\mathrm{H}}$ showed that human activities are adverse to the growth of vegetation and human-dominated land degradation occurs.

The slope value of actual NPP $\left(\mathrm{S}_{\mathrm{A}}\right)$ represents the vegetation dynamic or desertification dynamic. In this paper, positive $S_{A}$ represents desertification reversion, while negative $S_{A}$ indicates desertification expansion. The quantitative assessment method was based on Wessels et al. (2008) and Xu et al. (2010). Six possible scenarios can be defined by the slope of actual NPP, potential NPP and HNPP (Table 2).

\section{Results}

\subsection{Spatial and temporal dynamic of actual NPP and potential NPP}

The mean actual NPP of the Heihe River Basin from 2001 to 2010 was calculated using the CASA model and GIS method (Fig. 3a). The mean actual NPP showed obvious spatial heterogeneity. Areas with mean actual NPP larger than $450 \mathrm{~g} \mathrm{C} /\left(\mathrm{m}^{2} \cdot \mathrm{a}\right)$ were scattered in the southeast of Sunan county with good vegetation growth conditions. Areas with mean actual NPP between 350 and $450 \mathrm{~g} \mathrm{C} /\left(\mathrm{m}^{2} \cdot \mathrm{a}\right)$ were mainly scattered in the regions with relatively abundant water resources and vegetation such as Sunan, Shandan, Qilian and Minle counties. Areas with mean actual NPP ranging from 250 to $350 \mathrm{~g} \mathrm{C} /\left(\mathrm{m}^{2} \cdot \mathrm{a}\right)$ were widespread and included Qilian county, the southwest of Sunan county, the southwest of Shandan county, Minle county and Zhangye city, the fringe of the center of Lingze county, Gaotai county, and Jiuquan city. In short, these areas are characterized by abundant water and thermal resources, and relatively less human activities. Areas 
Table 2 Six scenarios for assessing the relative roles of climate change and human activities in desertification

\begin{tabular}{lllll}
\hline Desertification process & Scenario & $\mathrm{S}_{\mathrm{P}}$ & $\mathrm{S}_{\mathrm{H}}$ & Definition \\
\hline \multirow{2}{*}{$\begin{array}{llll}\text { Desertification reversion } \\
\left(\mathrm{S}_{\mathrm{A}}>0\right)\end{array}$} & Scenario 1 & $<0$ & $<0$ & Human-induced desertification reversion \\
& Scenario 2 & $>0$ & $>0$ & Climate-induced desertification reversion \\
& Scenario 3 & $>0$ & $<0$ & Both climate- and human-induced desertification reversion \\
& Scenario 1 & $>0$ & $>0$ & Human-induced desertification expansion \\
$\left(\mathrm{S}_{\mathrm{A}}<0\right)$ & Scenario 2 & $<0$ & $<0$ & Climate-induced desertification expansion \\
& Scenario 3 & $<0$ & $>0$ & Both climate- and human-induced desertification expansion \\
\hline
\end{tabular}

Note: $\mathrm{S}_{\mathrm{A}}$, the slope value of actual NPP; $\mathrm{S}_{\mathrm{P}}$, the slope value of potential NPP; $\mathrm{S}_{\mathrm{H}}$, the slope value of HNPP.
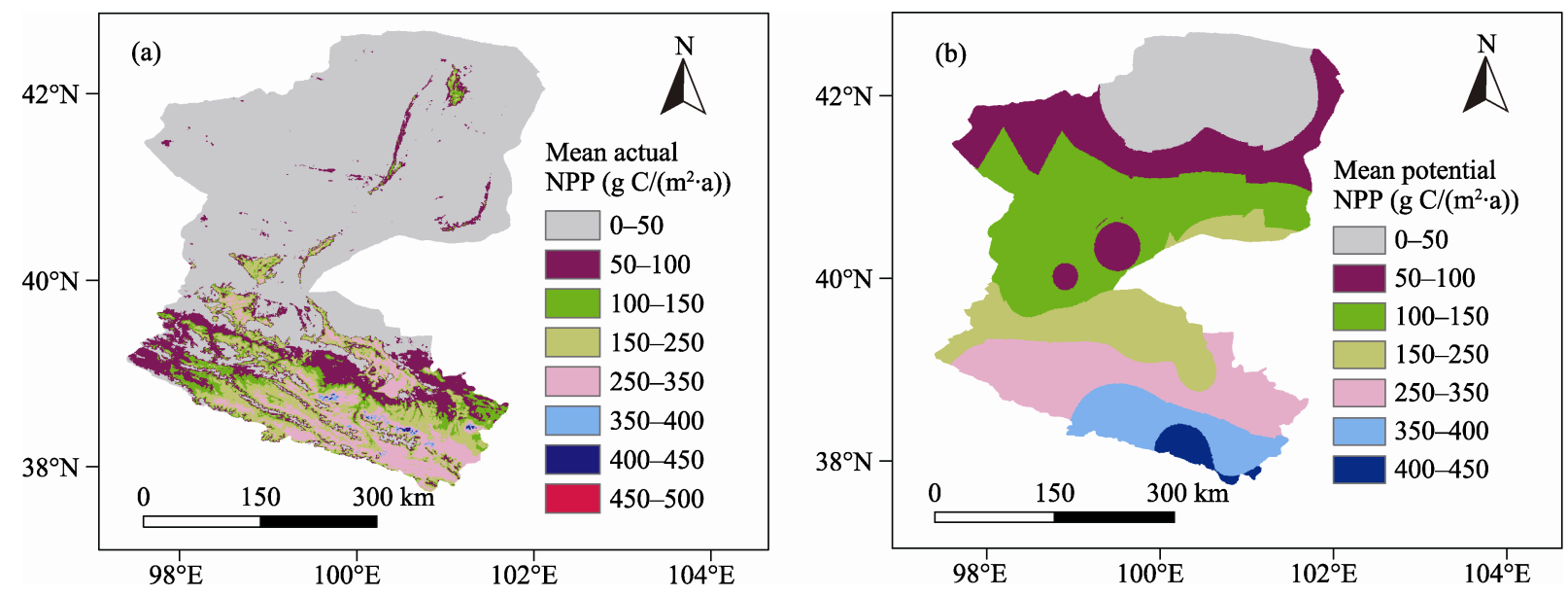

Fig. 3 Spatial distribution of (a) mean actual NPP and (b) mean potential NPP during 2001-2010

with mean actual NPP between 100 and $250 \mathrm{~g} \mathrm{C} /\left(\mathrm{m}^{2} \cdot \mathrm{a}\right)$ ran through the basin. Additionally, areas with mean actual NPP ranging from 50 to $100 \mathrm{~g} \mathrm{C} /\left(\mathrm{m}^{2} \cdot \mathrm{a}\right)$ were located in the transitional zone from desert to grassland. Areas with mean actual NPP of less than $50 \mathrm{~g}$ $\mathrm{C} /\left(\mathrm{m}^{2} \cdot \mathrm{a}\right)$ mainly included the midstream and downstream of the basin in the Badain Jaran Desert. Controlled by natural and human impacts, as well as by water resources, the mean actual NPP was larger in the upstream than in the midstream, and was least in the downstream of the Heihe River Basin (Table 3). From 2001 to 2010, vegetation growth seemed to have been strengthened. The maximum mean actual NPP of the whole Heihe River Basin was recorded in 2003, followed by 2007.

The mean actual NPP of different vegetation types from 2001 to 2010 was analyzed and showed significant differences (Fig. 4). The mean actual NPP of desert was smallest and ranged from 30 to $40 \mathrm{~g} \mathrm{C} /\left(\mathrm{m}^{2} \cdot \mathrm{a}\right)$. Forest had the largest annual mean actual NPP (280-340 g C/( $\left.\mathrm{m}^{2} \cdot \mathrm{a}\right)$ ), which was mainly distributed in the upstream near the Qilian Mountains. The mean actual NPP of grassland was between 150 and $200 \mathrm{~g}$ $\mathrm{C} /\left(\mathrm{m}^{2} \cdot \mathrm{a}\right)$, being widespread in the basin. The mean actual NPP of cropland and crop/natural vegetation mosaic was relatively high, ranging from 210 to $350 \mathrm{~g}$ $\mathrm{C} /\left(\mathrm{m}^{2} \cdot \mathrm{a}\right)$. Meanwhile, the maximum mean actual NPP of different vegetation types occurred in 2003.

Figure $3 \mathrm{~b}$ showed the spatial distribution of mean potential NPP. The overall distribution pattern was similar to that of the mean actual NPP, and represented a descending trend from the south (i.e. the upstream) to the north (i.e. the downstream) of the basin, along with the decreasing of precipitation and water resource supply. Areas with mean potential NPP from 400 to $450 \mathrm{~g} \mathrm{C} /\left(\mathrm{m}^{2} \cdot \mathrm{a}\right)$ were restricted to the south of Qilian county. The maximum mean potential NPP of the whole basin occurred in 2007, followed by 2010 (Table 3).

A contrast between the mean actual NPP and mean potential NPP values in Fig. 3 implies that human activities have important impacts on vegetation growth and carbon sequestration. In addition, areas with mean potential NPP of more than $150 \mathrm{~g} \mathrm{C} /\left(\mathrm{m}^{2} \cdot \mathrm{a}\right)$ account for 
Table 3 Mean actual NPP and mean potential NPP in different parts of the Heihe River Basin during 2001-2010

\begin{tabular}{|c|c|c|c|c|c|c|c|c|}
\hline \multirow{2}{*}{ Year } & \multicolumn{4}{|c|}{ Mean actual NPP $\left(\mathrm{g} \mathrm{C} /\left(\mathrm{m}^{2} \cdot \mathrm{a}\right)\right)$} & \multicolumn{4}{|c|}{ Mean potential NPP $\left(\mathrm{g} \mathrm{C} /\left(\mathrm{m}^{2} \cdot \mathrm{a}\right)\right)$} \\
\hline & Upstream & Midstream & Downstream & Whole basin & Upstream & Midstream & Downstream & Whole basin \\
\hline 2001 & 147.00 & 73.49 & 27.43 & 65.62 & 284.56 & 146.82 & 47.59 & 125.48 \\
\hline 2002 & 148.99 & 73.66 & 23.51 & 64.15 & 310.66 & 187.48 & 75.59 & 157.04 \\
\hline 2003 & 181.58 & 99.43 & 33.00 & 83.31 & 342.08 & 195.36 & 77.79 & 166.81 \\
\hline 2004 & 157.05 & 86.22 & 32.59 & 74.11 & 290.99 & 158.10 & 57.00 & 134.88 \\
\hline 2005 & 147.84 & 79.70 & 27.11 & 67.56 & 338.35 & 196.74 & 69.56 & 162.46 \\
\hline 2006 & 146.89 & 80.29 & 26.63 & 67.32 & 307.94 & 173.30 & 49.23 & 139.16 \\
\hline 2007 & 160.00 & 90.84 & 29.92 & 74.83 & 374.80 & 270.74 & 112.47 & 213.76 \\
\hline 2008 & 143.54 & 79.13 & 26.15 & 66.06 & 330.99 & 188.29 & 92.89 & 169.82 \\
\hline 2009 & 162.65 & 85.17 & 26.57 & 71.96 & 359.36 & 191.79 & 52.31 & 156.63 \\
\hline 2010 & 161.03 & 86.62 & 26.63 & 72.12 & 342.72 & 243.39 & 91.20 & 188.45 \\
\hline
\end{tabular}

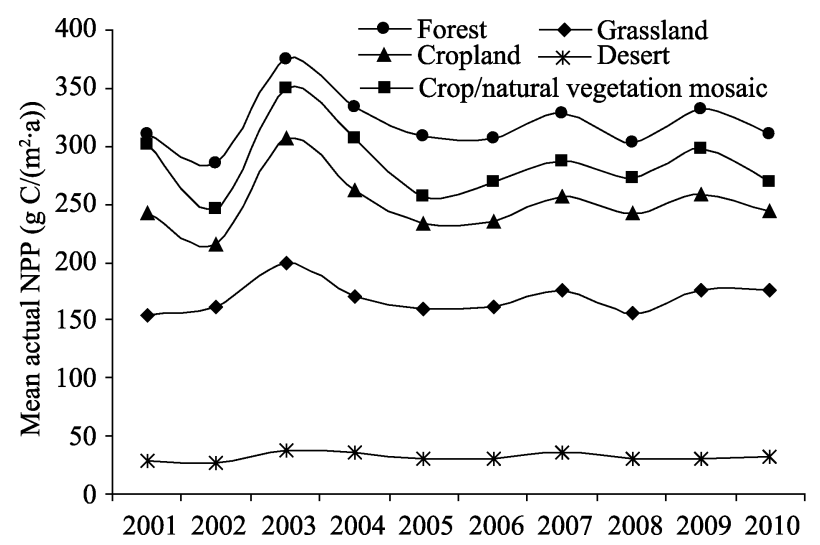

Fig. 4 Mean actual NPP variation of different vegetation types from 2001 to 2010

$40 \%$ of the study area; while areas with mean actual NPP of more than $150 \mathrm{~g} \mathrm{C} /\left(\mathrm{m}^{2} \cdot \mathrm{a}\right)$ account for only $17 \%$. Moreover, the areas with mean potential NPP of less than $50 \mathrm{~g} \mathrm{C} /\left(\mathrm{m}^{2} \cdot \mathrm{a}\right)$ were only distributed in the north of Ejin Banner and were much smaller compared with the case for mean actual NPP.

\subsection{Desertification dynamic analysis}

According to the previous method design, we analyzed the change trends of actual NPP, potential NPP and HNPP (Fig. 5). The overall trend of vegetation was degradation (i.e. desertification) based on the slope of actual NPP throughout the whole basin, although slightly increasing, moderate increasing, and significantly increasing of actual NPP occurred in parts of the basin (Fig. 5a). Moreover, the areas of vegetation degradation were large and occupied $61 \%$ of the whole basin, being especially distributed in the downstream with few water resources and serious human interference. While, the areas of vegetation restoration accounted for $39 \%$ of the study area, and the areas with significant actual NPP increase were scattered in Shandan, the south of Zhangye, and the northeast of Jiuquan.

The change trend of potential NPP was showed in Fig. 5b, and indicated that the climate was favorable to vegetation restoration in most parts of the basin except the north of the Ejin Banner where vegetation experienced slight degradation. The areas with climate-induced vegetation restoration accounted for $93.6 \%$ of the whole basin. Moderate vegetation restoration occurred in the midstream and most parts of the upstream, whereas slight vegetation restoration was found in the south of Sunan, Qilian, Mingle, Shandan, Zhangye and the Ejin Banner.

To estimate the impact of human activities on desertification, the slope of HNPP was calculated (Fig. 5c). As noted previously, positive $S_{H}$ indicates that human-induced desertification expansion occurs, and vice versus. Under the influence of human activities, areas with a negative $S_{H}$ were mainly distributed in the southeast of the basin, and the middle and north of Ejin Banner. Human-induced vegetation restoration only accounted for $8.9 \%$ of the whole basin; however, desertification expansion caused by human factors occurred in the rest of the basin. 


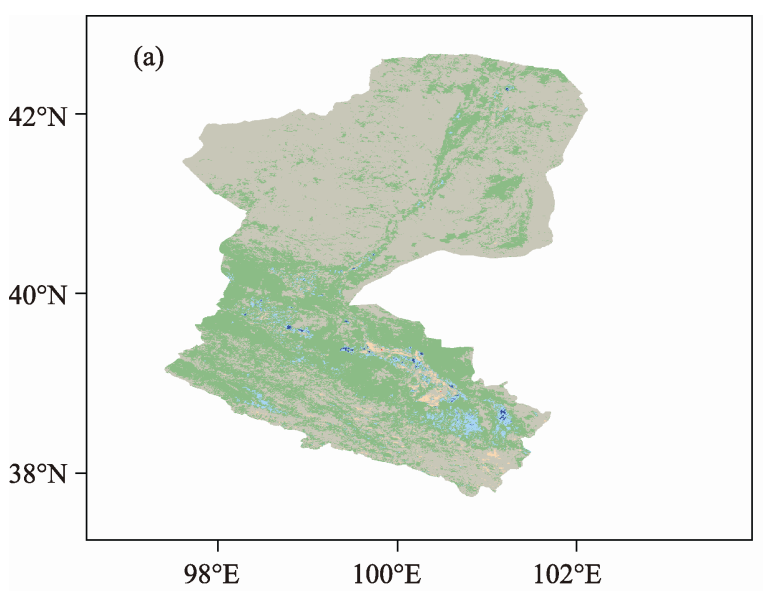

$\stackrel{N}{N}$

Significant decrease $(-23<\mathrm{S}<-8)$

Moderate decrease $(-8<\mathrm{S}<-3)$

Slight decrease $(-3<\mathrm{S}<0)$

Slight increase $(0<\mathrm{S}<3)$

Moderate increase $(3<\mathrm{S}<8)$

Significant increase $(8<\mathrm{S}<23)$
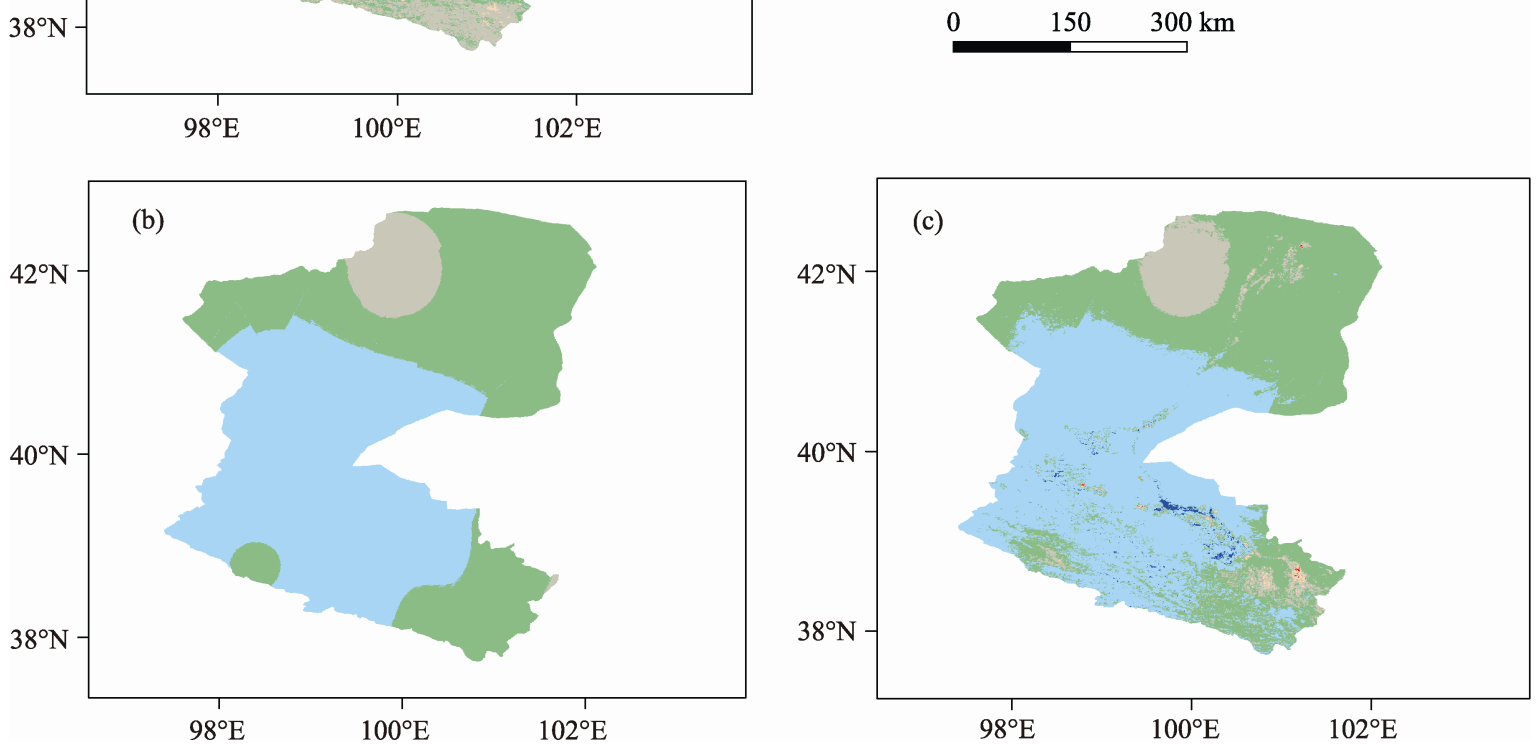

Fig. 5 Slope values for (a) actual NPP, (b) potential NPP, and (c) HNPP (human appropriation of NPP). S denotes the slope value for the three kinds of NPP and its unit is $\mathrm{g} \mathrm{C} /\left(\mathrm{m}^{2} \cdot \mathrm{a}\right)$.

\subsection{Relative roles of climate change and human activities in desertification}

The relative roles that climate change and human activities played in desertification expansion and reversion were assessed according to the methods listed in Table 2. The desertification process and the relative roles of the two factors showed obvious spatial heterogeneity (Fig. 6). Desertification expansion mainly occurred in the downstream of the Heihe River Basin near the Qilian Mountains; while, desertification reversion was found in the midstream and parts of the upstream and downstream of the basin. In addition, human-induced desertification expansion mainly occurred in Ejin Banner at the downstream and parts of the midstream and upstream; while human-induced desertification reversion was only scattered in the north of Ejin Banner. Climate-induced desertification expansion only occurred in the north of the Ejin Banner; but climate-induced desertification reversion was widespread in the whole basin, especially in the midstream and upstream.

Table 4 is the statistics of the relative roles of human and climate factors in desertification. As revealed, desertification expansion areas account for $61 \%$ of the study area, of which $90.5 \%\left(71,087 \mathrm{~km}^{2}\right)$ of the degradation was caused by human activities versus $8.6 \%$ $\left(6,761 \mathrm{~km}^{2}\right)$ resulted from climate change. Inversely, human-induced vegetation restoration accounted for only $1.5 \%\left(719 \mathrm{~km}^{2}\right)$ of total desertification reversion area, while $90.7 \%\left(45,030 \mathrm{~km}^{2}\right)$ was caused by climate change. The contribution of human and climate factors combined to desertification expansion area was $0.9 \%$ and to desertification reversion area was $7.8 \%$. Additionally, climate change was the dominant factor for the desertification reversion in the central section of the basin. However, human activities controlled desertification expansion in the downstream and parts of the midstream and upstream of the basin. 

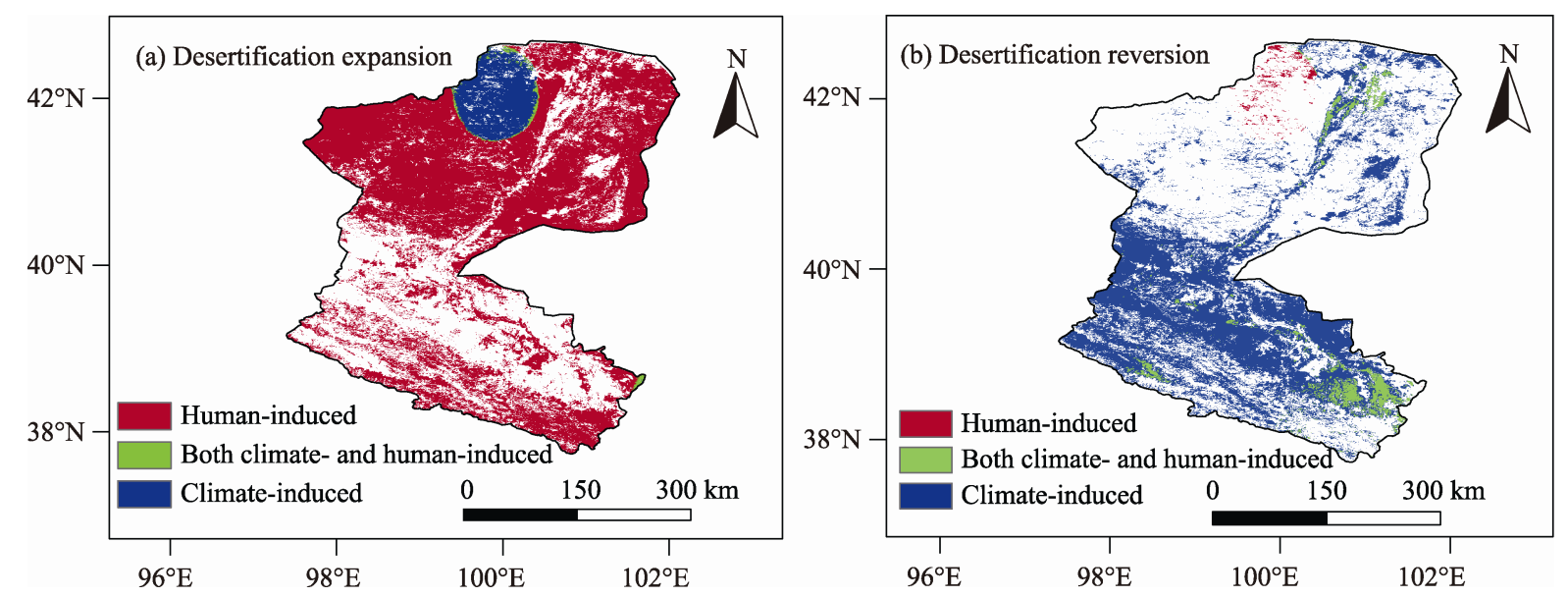

Fig. 6 Spatial distribution of the human and climate factors responsible for (a) desertification expansion and (b) desertification reversion from 2001 to 2010

Table 4 Desertification expansion and reversion caused by human and climate factors from 2001 to 2010

\begin{tabular}{lllll}
\hline & Desertification class & Human-induced & Climate-induced & Both climate- and human-induced \\
\hline \multirow{2}{*}{ Area $\left(\mathrm{km}^{2}\right)$} & Desertification expansion & 71,087 & 6,761 & 674 \\
& Desertification reversion & 719 & 45,030 & 3,893 \\
Total actual NPP & Desertification expansion & -252 & -8.4 & -2.4 \\
variation (Gg C) & Desertification reversion & 0.36 & 267.2 & 118.2 \\
\hline
\end{tabular}

Note: $\mathrm{Gg}=10^{9} \mathrm{~g}$

In order to further assess the relative roles of climate change and human activities in desertification process, we also calculated the desertification expansion and reversion based on total actual NPP variation (Table 4). Although the degradation area is larger than the restoration area, the total actual NPP increased by 123.1 Gg C from 2001 to 2010 and the mean actual NPP in restoration area $\left(7.8 \mathrm{~g} \mathrm{C} /\left(\mathrm{m}^{2} \cdot \mathrm{a}\right)\right)$ is larger than that in the degradation area $\left(-3.34 \mathrm{~g} \mathrm{C} /\left(\mathrm{m}^{2} \cdot \mathrm{a}\right)\right)$. And $95.9 \%$ of the total actual NPP decrease was caused by human activities, while $3.2 \%$ was caused by climate change; moreover, the contribution of climate change and human activities combined to total actual NPP decrease was $0.9 \%$. Nevertheless, the increase of total actual NPP caused by climate change and human activities was $69.3 \%$ and $0.1 \%$, respectively. The contribution of the two factors to desertification reversion reached $30.6 \%$ based on total actual NPP variation, and the reversion was mainly scattered in the north of Shandan, Minle, Gaotai, Jiuquan and the northwest of Qilian.

Overall, climate change is the dominant factor for the desertification reversion or vegetation restoration from 2001 to 2010, in the perspectives of both desertification areas and total actual NPP variation; and human activities is the dominant factor for desertification expansion and vegetation degradation.

\subsection{Relative roles of climate change and human activities in desertification for different vege- tation types}

The contribution of climate and human factors to desertification varied greatly in different vegetation types (Fig. 7). The contribution of human activities to desertification reversion in terms of the areas is larger than that of climate change for forest $(70.8 \%$ vs $17.0 \%$ ), grassland ( $53.2 \%$ vs $38.9 \%$ ), and crop/natural vegetation mosaic $(58.5 \%$ vs $12.6 \%)$; while the contribution of climate change to desertification reversion is larger than that of human activities for cropland (64.7\% vs $27.9 \%$ ) and desert (91.5\% vs $4.2 \%$; Fig. 7 a). All these demonstrated that human activities promoted the vegetation growth in forest, grassland and crop/natural vegetation mosaic, which indicated restoration programs such as the Grain for Green Pro- 

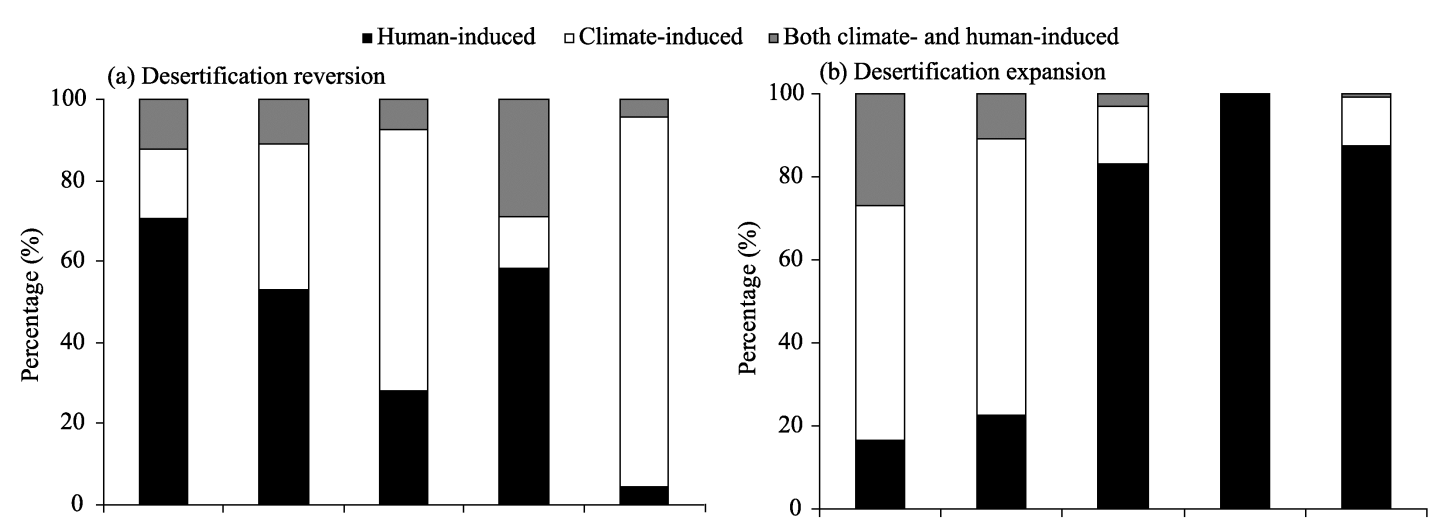

(c) Desertification reversion
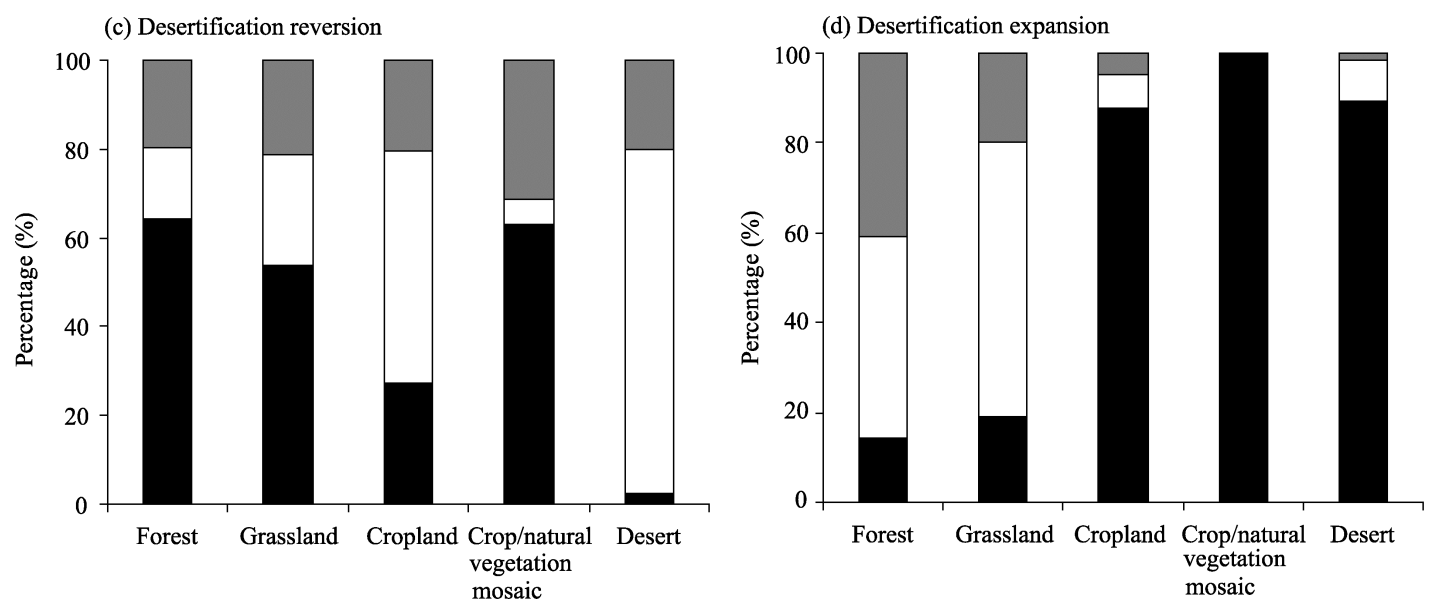

Fig. 7 The contribution of climate change, human activities and their combined impacts to land desertification for different vegetation types. (a) Desertification reversion and (b) desertification expansion based on areas; (c) desertification reversion and (d) desertification expansion based on actual NPP variation.

gram and the project of returning grazing land to grassland really benefit vegetation restoration. And climate change is more beneficial to desert and cropland productivity increase. On the contrary, in desertification expansion, the contribution of human activities is larger than that of climate change in cropland, crop/natural vegetation mosaic and desert; while in forest and grassland, the situation is opposite (Fig. 7b).

The relative roles of climate change and human activities in desertification for different vegetation types were also evaluated based on actual NPP variation (Figs. 7c and d). They showed similar rules with the above case which is based on desertification areas. Namely, human activities dominated vegetation actual NPP increase or desertification reversion in forest, grassland and crop/natural vegetation mosaic; climate change dominated desertification reversion in cropland and desert (Fig. 7c). For desertification expansion, human activities played a dominant role in cropland, crop/natural vegetation mosaic and desert; while climate change played a dominant role in forest and grassland (Fig. 7d).

\section{Discussion}

\subsection{Discussion of the methodology}

There is certain difficulty in distinguishing the relative roles of climate change and human activities in desertification process. Meanwhile, the traditional methodology mainly focused on statistical methods, such as regression analysis and principal component analysis (Chang et al., 2003; Zhang et al., 2003); however, it is always criticized for the lack of ecological process and driving mechanism involved in desertification dynamic analysis (Wrbka et al., 2004). Recently, several studies have been conducted to distinguish human-induced from climate-induced land degradation by comparing the actual with the potential vegetation 
conditions (Herrmann et al., 2005; Wessels et al., 2007).

According to the above methods, we selected NPP as an indicator to assess the relative roles of climate change and human activities in desertification, because NPP is a sensitive indicator to climatic and human impacts (Schimel, 1995) and a fundamental ecological variable to reflect vegetation dynamic. We used actual NPP to reflect the desertification dynamics, the potential NPP and HNPP to assess the impacts of climate change and human activities on desertification, respectively. Meanwhile, we calculated actual NPP variation based on the slope of actual NPP, which would more objectively reflect the vegetation productivity change from 2001 to 2010 . Although potential NPP and HNPP were used to assess the relative roles of climate change and human activities in desertification (Zika and Erb, 2009; Zhang et al., 2011), respectively, these studies have statistically analyzed the relative roles merely based on desertification areas. It is not reliable, as desertification area only reflects the desertification scope, while the actual NPP variation can reflect the desertification intensity. Therefore, the synthesized statistical analysis in this paper based on actual NPP variation and desertification areas may well explore the driving mechanism of desertification.

\subsection{Impacts of climate change on desertification process}

In the present study, by combining the analysis of the change trends of actual NPP, potential NPP, and HNPP, the relative roles of climate change and human activities in desertification expansion and reversion in the Heihe River Basin were determined.

Recently, some researchers reported that the climate changes from warm-dry to warm-wet in Northwest China (Shi et al., 2007). Our study confirmed this finding and Fig. 8 suggested that the annual precipitation showed an obvious increase trend and the annual mean temperature showed a fluctuating increase from 2001 to 2010. Furthermore, the potential NPP also increased with the increasing of precipitation and temperature. Meanwhile, the actual NPP increased with the rising precipitation, while slightly decreased with the rising temperature. Therefore both changes of

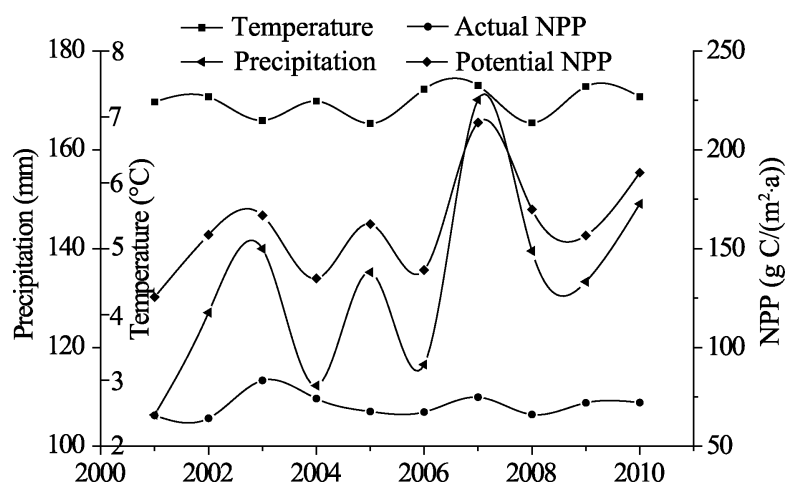

Fig. 8 Change trends of actual NPP and potential NPP and major climate factors from 2001 to 2010

temperature and precipitation promoted vegetation productivity increase in the Heihe River Basin, because the rise of temperature can lengthen the growing season of plants and strength photosynthesis, and thus promote vegetation activities (Fang et al., 2004); moreover, the rise of precipitation will benefit the growth of vegetation especially in dry lands (Herrmann et al., 2005). Climate change will benefit vegetation restoration or desertification reversion (Zheng et al., 2006). We also found that the climate change is the dominant factor for the desertification reversion from 2001 to 2010 in the Heihe River Basin (Fig. 6b and Table 4). However, Li et al. (2006) found that climate change was the dominant factor in desertification expansion, and its contribution reached $63.59 \%$ in Naiman Banner of Inner Mongolia since rising temperature and declining precipitation have led to environmental deterioration (Wang et al., 2010).

\subsection{Impacts of human activities on desertification process}

On the one hand, human interference, such as overgrazing, conversion of grassland to artificial oasis and other land uses, and excessive water consumption, will lead to land degradation. Some studies discovered that excessive water utilization in the midstream and upstream of the Heihe River Basin had caused the sharp decrease of water resources in the downstream of the basin (Liu et al., 2009), which ultimately led to desert increase by $85.1 \%$ and oasis decrease by $25.5 \%$ in the downstream (Wang et al., 2006). In recent years, Qilian county has become one of the most serious desertification regions in the Heihe River Basin because 
of overcutting and overgrazing $(\mathrm{Xu}$ and $\mathrm{Li}, 2011)$. Our study confirmed that abound $67 \%$ of the desertification expansion occurred in the downstream (Fig. 9). Furthermore, our study found that human activities is the dominant driving factor for desertification expansion and its contribution reached $90.5 \%$ for the total degradation area (Table 4). These results coincide with the reports from other researchers (Ma et al., 2007; Zhang et al., 2011).

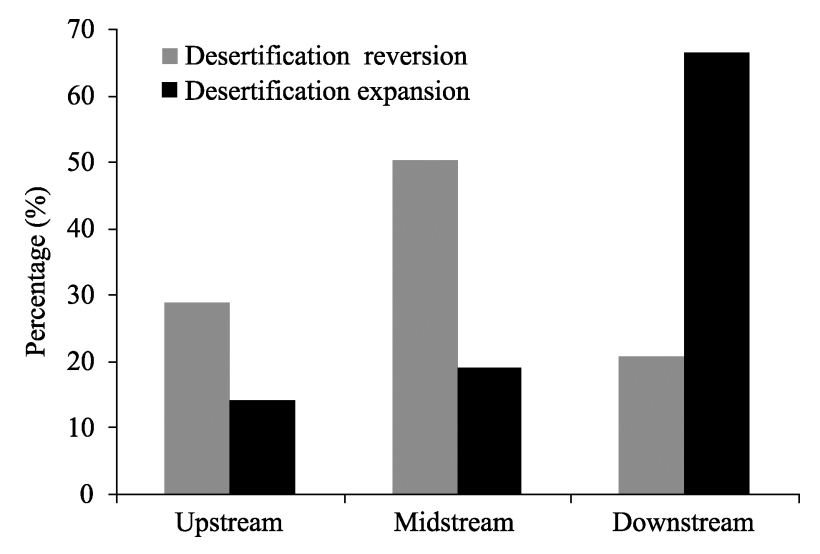

Fig. 9 Percentage of desertification reversion and expansion at the upstream, midstream and downstream of the Heihe River Basin from 2001 to 2010

On the contrary, human activities, such as a longtime enclosure and the project of returning grazing land to grassland, promote desertification reversion, but is responsible for only $1.5 \%$ of the total restoration area, which is far less than that from climate change (90.7\%; Table 4). Besides, human-induced desertification reversion was scattered only in the north of Ejin Banner, mainly because the government began to transfer water to the downstream since 2000, leading to the rise of water body area and promotion of vegetation (Guo et al., 2002; Yang et al., 2004). However, some studies concluded that human activities dominate desertification reversion (Gao et al., 2005; $\mathrm{Li}$ et al., 2007; $\mathrm{Xu}$ et al., 2010; Zhang et al., 2011). The roles of human activities largely depend on the effectiveness of government policies and programs. For example, Horqin Sandy Land and the southern Mu Us Sandy Land have experienced an obvious desertification reversion since the 1990s (Wang et al., 2004a), and Wang et al. (2012) also reported that the desertification control in Yulin region has achieved better results under a series of positive measures taken by the government. So, we can conclude that the dominant factors of desertification expansion or reversion depend on regional climate change, social-economic conditions and management practices.

In our study, we also found that the positive effect of the combination of climate and human factors on desertification reversion is obviously based on total actual NPP variation and its contribution reached $30.6 \%$, which is much larger than that on desertification expansion $(0.9 \%$; Table 4$)$. This demonstrated that the positive effect of the two factors combined in desertification reversion or vegetation restoration is dramatic. Therefore, we should enhance the effectiveness of governmental measures and policies in the Heihe River Basin to prevent the desertification expansion under the condition of climate change.

\section{Conclusions}

The Heihe River Basin has experienced significant environmental change in response to climate change and human activities from 2001 to 2010. Actual NPP was selected as an indicator to reflect desertification dynamics; potential NPP and HNPP were selected to quantitatively assess the impact of climate change and human activities on desertification, respectively. The results showed that in the Heihe River Basin, desertification expansion accounts for $61 \%$ of the whole basin area and $90.5 \%$ of the desertification expansion was caused by human activities versus only $8.6 \%$ was caused by climate change. On the contrary, $1.5 \%$ of the desertification reversion was caused by human activities and $90.7 \%$ was caused by climate change.

Furthermore, the relative roles of the two driving factors in desertification based on total actual NPP variation were also analyzed, and the results indicated that $95.9 \%$ of the vegetation degradation was caused by human activities versus $3.2 \%$ was induced by climate change. In contrast, $0.1 \%$ of the vegetation restoration was caused by human activities and $69.3 \%$ was caused by climate change. The contribution of the two factors combined to desertification reversion reached $30.6 \%$ based on total actual NPP variation, which is much larger than that to desertification ex- 
pansion $(0.9 \%)$. Therefore, climate change is the dominant factor for desertification reversion or vegetation restoration based on both desertification areas and total actual NPP variation; and human activities dominated desertification expansion or vegetation degeneration. During the study period, the increase of temperature and precipitation benefited vegetation restoration, but human interference such as overgrazing, extensive cutting, conversion of grassland and forest to farmland, and extensive water consumption in the midstream and upstream of the basin, played a major role in desertification expansion.

In addition, the relative roles of climate change and human activities had great spatial heterogeneity. Climate change dominated vegetation restoration in the whole basin, especially in the midstream and upstream, but climate-induced desertification expansion was restricted to the north of the Ejin Banner. Human-induced desertification expansion mainly occurred in Ejin Banner at the downstream and parts of the midstream and upstream, but human-induced desertification reversion was restricted only to the north of the Ejin Banner.

\section{Acknowledgments}

This work was supported by the National Basic Research Program of China (2010CB950702), the National High Technology Research and Development Program of China (2007AA10Z231), the National Natural Science Foundation of China (40871012, J1103512, J1210026), the Asia-Pacific Network (ARCP-2012-SP25-Li), and the Australian Agency for International Development (64828). We are grateful to Dr. Victor SQUIRES from University of Adelaide, Australia for his help in modifying the language. We also thank the China Meteorological Data Sharing Service System for providing climate datasets.

\section{References}

Alcamo J, Bennett E M. 2003. Ecosystems and Human Well-Being: A Framework for Assessment. Washington: Island Press.

Chang X L, Lu C X, Gao Y B. 2003. Impacts of human economic activities on wind and sand environment in Kerqin sandy land. Resources Science, 25(5): 78-83.

Fang J Y, Piao S L, He J Y, et al. 2004. Increasing terrestrial vegetation activity in China, 1982-1999. Science in China: Life Sciences, 47(3): 229-240.
Field C B, Randerson J T, Malmström C M. 1995. Global net primary production: combining ecology and remote sensing. Remote Sensing of Environment, 51(1): 74-88.

Field C B, Behrenfeld M J, Randerson J T, et al. 1998. Primary production of the biosphere: integrating terrestrial and oceanic components. Science, 281(5374): 237-240.

Gao X H, Wang Y M, Wang J H, et al. 2005. Analysis on desertification dynamics based on remote sensing and GIS in zone along the Great Wall in northern Shaanxi province. Journal of Desert Research, 25(1): 63-67.

Guo N, Yang L F, Wang J L. 2002. A study of ecological environment in Heihe valley area through meteorology satellite monitoring. Plateau Meteorology, 21(3): 267-273.

Hai C X, Ma L, Wang X M, et al. 2002. Main factors analysis about soil desertification in typical section of interlock area of farming and pasturing: the case of Zhangbei county, Bashang area of Hebei province. Geographical Research, 21(5): 543-550.

Hanafi A, Jauffret S. 2008. Are long-term vegetation dynamics useful in monitoring and assessing desertification processes in the arid steppe, southern Tunisia. Journal of Arid Environments, 72(4): 557-572.

Herrmann S M, Anyamba A, Tucker C J. 2005. Recent trends in vegetation dynamics in the African Sahel and their relationship to climate. Global Environmental Change, 15(4): 394-404.

Le Houérou H N. 1996. Climate change, drought and desertification. Journal of Arid Environments, 34(2): 133-185.

Li S, Zheng Y, Luo P, et al. 2007. Desertification in western Hainan Island, China (1959 to 2003). Land Degradation \& Development, 18(5): 473-485.

Li X, Lu L, Cheng G D, et al. 2001. Quantifying landscape structure of the Heihe River Basin, north-west China using FRAGSTATS. Journal of Arid Environments, 48(4): 521-535.

Li Z S, He L M, Wang T. 2006. A method for determining the contribution of natural factors on sandy pasture desertification. Journal of Desert Research, 26(5): 687-692.

Lieth H, Box E. 1972. Evapotranspiration and primary productivity: C.W. Thornthwaite Memorial Model. Publications in Climatology, 25(3): 37-46.

Lieth H. 1975. Modeling the primary production of the world. In: Lieth H, Whittaker R H. Primary Productivity of the Biosphere. Berlin: Springer, 237-283.

Liu W, Wang T, Cao S K, et al. 2009. Evolution and variation of land desertification in Heihe River Basin and its effection factors. Journal of Arid Land Resources and Environment, 23(1): 35-43.

Lu A G, Pan D Q, Li X L, et al. 2008. Eco-environmental changes and ecological restoration on Ejina oasis. Journal of Arid Land Resources and Environment, 22(6): 39-43.

Ma M G, Frank V. 2006. Interannual variability of vegetation cover in the Chinese Heihe River Basin and its relation to meterological parameters. International Journal of Remote Sensing, 27(16): 3473-3486.

Ma Y H, Fan S Y, Zhou L H, et al. 2007. The temporal change of driving factors during the course of land desertification in arid region of 
North China: the case of Minqin county. Environmental Geology, 51(6): 999-1008.

Nicholson S. 2005. On the question of the "recovery" of the rains in the West African Sahel. Journal of Arid Environments, 63(3): 615-641.

Nicholson S E, Tucker C J, Ba M B. 1998. Desertification, drought, and surface vegetation: an example from the West African Sahel. Bulletin of the American Meteorological Society, 79(5): 815-829.

Potter C S, Randerson J T, Field C B, et al. 1993. Terrestrial ecosystem production-a process model-based on global satellite and surface data. Global Biogeochemical Cycles, 7(4): 811-841.

Prince S D, De Colstoun E B, Kravitz L L. 1998. Evidence from rain-use efficiencies does not indicate extensive Sahelian desertification. Global Change Biology, 4(4): 359-374.

Rasmussen K, Fog B, Madsen J E. 2001. Desertification in reverse? Observations from northern Burkina Faso. Global Environmental Change, 11(4): 271-282.

Ruimy A, Saugier B, Dedieu G. 1994. Methodology for the estimation of terrestrial net primary production from remotely sensed data. Journal of Geophysical Research: Atmospheres, 99(D3): 5263-5283.

Schimel D S. 1995. Terrestrial biogeochemical cycles: global estimates with remote sensing. Remote Sensing of Environment, 51(1): 49-56.

Shi Y F, Shen Y P, Kang E, et al. 2007. Recent and future climate change in northwest China. Climatic Change, 80(3-4): 379-393.

State Forestry Administration. 2007. The Third Communique of Desertification and Sandy Desertification in China. [2007-06-14]. http://www.gov.cn/ztzl/fszs/content_650487.htm.

Sun W, Li B S. 2002. The relation between coupling among the principal components of desertification factors and desertification in rear hills of Bashang since 1950. Geographical Research, 21(3): 391-398.

UNCCD. 1994. United Nations Convention to Combat Drought and Desertification in Those Countries Experiencing Serious Droughts and/or Desertification, Particularly in Africa. A/AC.241/27. 14-15 October. France: Paris.

Verón S R, Paruelo J M, Oesterheld M. 2006. Assessing desertification. Journal of Arid Environments, 66(4): 751-763.

Wang J, Shen G L, Li C Y, et al. 2010. Analysis on climate change of Tongliao in recent 50 years. Meteorology Journal of Inner Mongolia, 19(6): 18-22.

Wang T, Zhu Z D. 2003. Study on sandy desertification in China: 1. definition of sandy desertification and its connotation. Journal of Desert Research, 23(3): 209-214.

Wang T, Zhu Z D, Zhao H L. 2004a. Study on sandy desertification in China: 4. strategy and approach for combating sandy desertification. Journal of Desert Research, 24(2): 115-123.

Wang T, Sun J G, Han H, et al. 2012. The relative role of climate change and human activities in the desertification process in Yulin region of northwest China. Environmental Monitoring and Assessment,
184(12): 7165-7173.

Wang X M, Dong Z B, Zhang J W, et al. 2004b. Modern dust storms in China: an overview. Journal of Arid Environments, 58(4): 559-574.

Wang X M, Chen F H, Dong Z B. 2006. The relative role of climatic and human factors in desertification in semiarid China. Global Environmental Change, 16(1): 48-57.

Wessels K J, Prince S D, Malherbe J, et al. 2007. Can human-induced land degradation be distinguished from the effects of rainfall variability? A case study in South Africa. Journal of Arid Environments, 68(2): 271-297.

Wessels K J, Prince S D, Reshef I. 2008. Mapping land degradation by comparison of vegetation production to spatially derived estimates of potential production. Journal of Arid Environments, 72(10): 1940-1949.

Wrbka T, Erb K, Schulz N B, et al. 2004. Linking pattern and process in cultural landscapes. An empirical study based on spatially explicit indicators. Land Use Policy, 21(3): 289-306.

Xu B Y, Li D L. 2011. Discussion on desertification combating and the countermeasures in Hexi corridor. Chinese Agricultural Science Bulletin, 27(11): 266-270.

Xu D Y, Kang X W, Zhuang D F, et al. 2010. Multi-scale quantitative assessment of the relative roles of climate change and human activities in desertification-a case study of the Ordos Plateau, China. Journal of Arid Environments, 74(4): 498-507.

Yang X G, Zhang C J, Ye Q, et al. 2004. Some facts of creeping environment problems in Hexi region of Gansu. Arid Meteorology, 22(1): 65-68.

Yu D Y, Shi P J, Han G Y, et al. 2011. Forest ecosystem restoration due to a national conservation plan in China. Ecological Engineering, 37(9): 1387-1397.

Zhang C X, Wang X M, Li J C, et al. 2011. Roles of climate changes and human interventions in land degradation: a case study by net primary productivity analysis in China's Shiyanghe Basin. Environment Earth Sciences, 64(8): 2183-2193.

Zhang Y S, Wang L X, Zhang H Q, et al. 2003. Influence of environmental factor changes on desertification process in Shule River. Resource Science, 25(6): 60-65.

Zheng Y R, Xie Z X, Robert C, et al. 2006. Did climate drive ecosystem change and induce desertification in Otindag sandy land, China over the past 40 years? Journal of Arid Environments, 64(3): 523-541.

Zhu W Q, Pan Y Z, He H, et al. 2006. Simulation of maximum light use efficiency for some typical vegetation types in China. Chinese Science Bulletin, 51(4): 457-463.

Zika M, Erb K. 2009. The global loss of net primary production resulting from human-induced soil degradation in drylands. Ecological Economics, 69(2): 310-318. 